\title{
Immunization against Hepatitis A
}

\author{
Daniel Shouval \\ Liver Unit, Institute for Gastroenterology and Hepatology, Hadassah-Hebrew University Hospital, Jerusalem \\ 91120, Israel \\ Correspondence: shouval@hadassah.org.il
}

Worldwide, there are multiple formaldehyde-inactivated and at least two live attenuated hepatitis $A$ vaccines now in clinical use. The impressive immunogenicity of inactivated vaccines is reflected in rapid seroconversion rates, enabling both preexposure and postexposure prophylaxis. Universal childhood vaccination programs targeting young children have led to significant drops in the incidence of hepatitis A both in toddlers and in susceptible nonimmune adults in regions with intermediate endemicity for hepatitis A. Although the safety of inactivated vaccines is well established, further studies are needed concerning the implications of fecal virus shedding by recipients of attenuated vaccines, as well as the longterm persistence of immune memory in children receiving novel immunization schedules consisting of single doses of inactivated vaccines.

$\mathrm{H}$ epatitis A virus (HAV) infection is a vaccine-preventable disease (Lemon et al. 2017). General measures of protection include adequate personal hygiene, especially in food handlers and in nursing staff at day-care centers, quality control and maintenance of a safe water and food supply, and proper sanitation. Specific measures include (1) short-term pre- and postexposure prophylaxis with immune serum globulin (IG), (2) long-term pre- and postexposure active prophylaxis using formaldehyde-inactivated HAV vaccines, and (3) preexposure prevention using a live attenuated vaccine. This review provides an outline of the current means for immunization against HAV infection for short- and long-term protection.

\section{IMMUNE GLOBULIN FOR SHORT-TERM PROTECTION AGAINST HEPATITIS A}

IG, prepared through ethanol fractionation of pooled human plasma, was introduced into clin- ical practice $\sim 70$ years ago (Stokes et al. 1948). A review of 13 clinical trials, including 567,476 participants randomized to pre- or postexposure prophylaxis and a meta-analysis of six randomized trials, reveals that IG is $80 \%-90 \%$ effective in reducing the incidence of acute hepatitis $A$ postexposure. Cumulative experience suggests that, depending on when it is administered, postexposure prophylaxis with IG may prevent or ameliorate clinical symptoms of hepatitis A but not prevent "silent" asymptomatic infection. Protection starts within hours of intramuscular (i.m.) injection of IG into the gluteal or deltoid muscle, although the duration of protection is not fully established. The length of protection is dose dependent, and following injection of 0.02 or $0.06 \mathrm{~mL} / \mathrm{kg}$ ranges from $\sim 12$ to 20 weeks, respectively, but it was found to extend to 12 months in one clinical trial (Zaaijer et al. 1993; Advisory Committee on Immunization Practices 2006; Liu et al. 2009). Postexposure prophylaxis is only effective with IG if it is admin-

Editors: Stanley M. Lemon and Christopher Walker

Additional Perspectives on Enteric Hepatitis Viruses available at www.perspectivesinmedicine.org

Copyright (C) 2019 Cold Spring Harbor Laboratory Press; all rights reserved; doi: 10.1101/cshperspect.a031682

Cite this article as Cold Spring Harb Perspect Med 2019;9:a031682 
D. Shouval

istered within 2 weeks of exposure (Victor et al. 2007). The mechanism involved in IG protection against HAV is not fully established. Saul Krugman showed in 1976 that it is possible to neutralize the infectivity of HAV in serum by in vitro incubation with high titer IG before inoculation into susceptible individuals (Krugman 1976). Later, it was shown that nonenveloped HAV can readily be neutralized when pretreated with anti-HAV antibodies before inoculation onto cultured cells (Lemon et al. 1997). It has been suggested that anti-HAV (IgG) antibodies may interfere with HAV uptake in the gut, or neutralize circulating quasi-enveloped virus following endocytosis into the hepatocyte (Walker et al. 2015). Circulating quasi-enveloped HAV virions are resistant to neutralization before endocytosis, as the capsid (which is targeted by neutralizing antibodies) is cloaked by membranes (Feng et al. 2013).

IG has had an excellent safety record when prepared according to standards approved by the U.S. Food and Drug Administration (FDA), and may be administered during pregnancy and lactation. Local reactions at the injection site were reported in $13 \%$ of recipients in a small, randomized trial (Shouval et al. 1993). IG administration is, however, contraindicated in persons with IgA deficiency who may develop anaphylaxis (Ellis and Henney 1969). IG may interfere with the response to attenuated live vaccines such as those for measles, mumps, rubella (MMR), or varicella for a period of 2 to 20 weeks (Advisory Committee on Immunization Practices 2006). No information is yet available regarding pre- or coadministration of IG with attenuated live hepatitis A vaccines used in China, but common sense suggests avoiding such a combined intervention. Concomitant administration of formaldehyde-inactivated HAV vaccines with IG may temporarily interfere with in vivo generation of protective antiHAV IgG antibodies. However, despite the blunting of anti-HAV responses, recipients of combined passive/active immunization against HAV usually respond to a booster injection of the HAV vaccine (Green et al. 1993), suggesting the development of immune memory against HAV.
The use of IG for pre- and postexposure prophylaxis against HAV is gradually declining worldwide for several reasons. These include its high cost, declining herd immunity against HAV in developed countries, which is leading to low anti-HAV IgG titers in plasma pools, the short duration of protection afforded by IG, and widespread availability of formaldehyde-inactivated HAV vaccines. Such vaccines have been shown to be equally effective in inducing rapid postexposure prophylaxis, provided the first dose of vaccine is administered within 2 weeks of exposure (Victor et al. 2007), although protection lasts much longer than with IG. The declining antiHAV antibody titers in potential plasma donors have led to establishment of an international standard for HAV immunoglobulin preparation (Zaaijer et al. 1993; Ferguson et al. 2000); IG should contain $\geq 100 \mathrm{IU} / \mathrm{mL}$ of anti-HAV IgG antibodies according to recommendations of the European Pharmacopeia. A recent survey by the U.S. Centers for Disease Control and Prevention of the HAV-neutralizing potential of IG preparations manufactured in Western countries revealed an anti-HAV potency $>100 \mathrm{IU} /$ $\mathrm{mL}$ in only two of nine preparations tested (Tejada-Strop et al. 2017). Modeling suggests that the duration of protection against HAV using such IG products falls short of 3 months, and that the current recommended dosing of IG should be increased unless the plasma pools used for production are "harvested" from hyperimmunized donors. It was also suggested that variance in anti-HAV IgG assay specificity would be reduced by adopting a standardized functional neutralization assay for licensing of IG. All in all, however, the use of IG is declining worldwide, and should be restricted to pre- or postexposure prophylaxis only in regions where timely administration of inactivated HAV vaccine is not possible, or immune responses to vaccine are expected to be suboptimal because of age or other patient characteristics.

\section{ACTIVE IMMUNIZATION AGAINST HEPATITIS A}

A number of "active" hepatitis A vaccines have been developed following an extended series of 
pivotal discoveries made during the last three decades of the 20th century (Hilleman 1993; Martin and Lemon 2006; Binn and Lemon 2010). These breakthroughs included the discovery of HAV via immune electron microscopy (Feinstone 1973), development of diagnostic serologic tests for hepatitis A, and much later molecular probes (Nainan et al. 2006), and propagation of HAV, initially in vivo, in nonhuman primates, and then in vitro in cell cultures, leading to the development of cell culture-adapted, attenuated viral strains (Provost and Hilleman 1979; Purcell et al. 1992). Two types of HAV vaccines are currently in clinical use, namely, formaldehyde ("killed") and live attenuated vaccines (Shouval 2010; Cui et al. 2014). Most countries have opted for use of formaldehydeinactivated HAV vaccines for pre- and postexposure prophylaxis because of superior immunogenicity and to avoid the potential risk of reversion to virulence of live attenuated virus. In China, both live and inactivated vaccines are available (Cui et al. 2014). The success of two randomized controlled trials of formaldehyde-inactivated HAV vaccines in the United States and in Thailand, conducted in children in the early 1990s, paved the way for the introduction and licensure of such vaccines worldwide (Werzberger et al. 1992; Innis et al. 1994; WHO 2012). Currently licensed HAV vaccines are listed in Table 1.

\section{HEPATITIS A VACCINES}

Multiple formaldehyde-inactivated HAV vaccines are manufactured in Europe, the United States, and Asia, and at least two attenuated vaccines are produced in China and elsewhere (Table 1). All HAV vaccines, whether inactivated or live, contain HAV propagated in cell culture, which leads generally to its attenuation. Viral attenuation results from serial passages in different human and nonhuman mammalian cells and has been associated in one strain (HM175) with a small number of mutations in the nonstructural proteins of the virus, particularly in the 2B and 2C proteins (Funkhouser et al. 1994; Emerson et al. 2002; Martin and Lemon 2006; $\mathrm{Xu}$ and Wang 2014).
The inactivated vaccines, HAVRIX, VAQTA, and AVAXIM contain purified, formaldehyde-treated cell culture-derived HAV adsorbed to aluminum hydroxide; aimugen contains highly-purified inactivated virus, but is aluminum-free. The HAV antigen in EPAXAL is formulated in influenza-reconstituted virosomes. VAQTA, HAVRIX, EPAXAL, HEALIVE, and the Chinese Lv-8-inactivated HAV vaccine, are at present preservative-free (Shouval 2010). The biological activity of inactivated hepatitis A vaccines is measured either by an in vivo relative potency assay or by an immunochemical determination of antigen. A reference standard, calibrated in international units (IUs), has been developed in Europe for the in vitro potency assay of formaldehyde-inactivated vaccines (Stalder et al. 2010; Morgeaux et al. 2015).

Inactivated hepatitis $\mathrm{A}$ vaccines should be refrigerated at $2^{\circ} \mathrm{C}$ to $8^{\circ} \mathrm{C}$; the vaccines should not be frozen. The shelf-life for inactivated hepatitis A vaccines ranges between 24 and 36 months, as specified by the manufacturers (Shouval 2010; Kumru et al. 2014). Most HAV vaccines come in liquid form, except for the Japanese formaldehyde-inactivated aimugen vaccine that is freeze-dried, as are the Chinese LA- 1 and $\mathrm{H} 2$ live attenuated vaccines (Table 1).

In China, three formaldehyde-inactivated and two live attenuated monovalent HAV vaccines are available (Table 1). Vaccine-induced protection against $\mathrm{HAV}$ infection is defined as an anti-HAV titer $\geq 20 \mathrm{mIU} / \mathrm{mL}$. These vaccines were integrated into the Chinese national immunization program beginning in 2007 and are recommended for all 18-month-old toddlers and older children. Live attenuated vaccines are administered as one subcutaneous (s.c.) dose while the formaldehyde-inactivated vaccines are given as two i.m. doses, administered 6 months apart. Related live attenuated HAV vaccines are licensed in India, Guatemala, Philippines, and Thailand under different brand names (Cui et al. 2014).

In addition to monovalent HAV vaccines, combination formaldehyde-inactivated vaccines have been developed in Europe against HAV and HBV, as well as HAV and typhoid (Van Damme and Van Herck 2004; Shouval 2010). 
D. Shouval

Table 1. Licensed monovalent hepatitis A virus vaccines manufactured in the United States, Europe, Japan, and China

\begin{tabular}{|c|c|c|c|c|c|c|c|}
\hline \multirow[b]{2}{*}{ Vaccine type } & \multirow{2}{*}{$\begin{array}{l}\text { HAV } \\
\text { strain }\end{array}$} & \multirow[b]{2}{*}{ Trade name $^{\mathrm{a}}$} & \multirow[b]{2}{*}{ Adjuvant } & \multicolumn{3}{|c|}{ Administration (dosage) } & \multirow[b]{2}{*}{ Manufacturer(s) } \\
\hline & & & & Route & Pediatric & Adult & \\
\hline $\begin{array}{l}\text { Formaldehyde- } \\
\text { inactivated }\end{array}$ & HM-175 & HAVRIX & $\begin{array}{l}\text { Alum } \\
\text { hydroxide }\end{array}$ & i.m. & $720 \mathrm{EU}$ & $1440 \mathrm{EU}$ & $\begin{array}{l}\text { GlaxoSmikthKline } \\
\text { Biologicals }\end{array}$ \\
\hline $\begin{array}{l}\text { Formaldehyde- } \\
\text { inactivated }\end{array}$ & CR-326 & VAQTA & $\begin{array}{l}\text { Alum } \\
\text { hydroxide }\end{array}$ & i.m. & $25 \mathrm{U}$ & $50 \mathrm{U}$ & MerckVaccines \\
\hline $\begin{array}{l}\text { Formaldehyde- } \\
\text { inactivated }\end{array}$ & GBM & AVAXIM & $\begin{array}{l}\text { Alum } \\
\text { hydroxide }\end{array}$ & i.m. & $80 \mathrm{U}$ & $160 \mathrm{U}$ & Sanofi-Pasteur \\
\hline $\begin{array}{l}\text { Formaldehyde- } \\
\text { inactivated }\end{array}$ & RG-SB & EPAXAL $^{\mathrm{b}}$ & Virosome & i.m. & $24 \mathrm{U}$ & $24 \mathrm{U}$ & Crucell/Berna Biotech \\
\hline $\begin{array}{l}\text { Formaldehyde- } \\
\text { inactivated }\end{array}$ & TZ-84 & Healive & $\begin{array}{l}\text { Alum } \\
\text { hydroxide }\end{array}$ & i.m. & $250 \mathrm{U}$ & $500 \mathrm{U}$ & Sinovac Biotech \\
\hline $\begin{array}{l}\text { Formaldehyde- } \\
\text { inactivated, } \\
\text { freeze-dried }\end{array}$ & KRM003 & Aimugen & Alum-free & i.m. & $0.5 \mu \mathrm{g}$ & $0.5 \mu \mathrm{g}$ & $\begin{array}{l}\text { Chemo-Sero- } \\
\text { Therapeutic } \\
\text { Research Institute, } \\
\text { Japan; Kaketsuken }\end{array}$ \\
\hline $\begin{array}{l}\text { Formaldehyde- } \\
\text { inactivated }\end{array}$ & Lv-8 & Weisairuian & $\begin{array}{l}\text { Alum } \\
\text { hydroxide }\end{array}$ & i.m. & $320 \mathrm{EU}$ & $640 \mathrm{EU}$ & $\begin{array}{l}\text { Institute of Medical } \\
\text { Biology, Chinese } \\
\text { Academy of Medical } \\
\text { Sciences }\end{array}$ \\
\hline $\begin{array}{l}\text { Formaldehyde- } \\
\text { inactivated }\end{array}$ & YN-5 & Veraxim & $\begin{array}{l}\text { Alum } \\
\text { hydroxide }\end{array}$ & i.m. & $800 \mathrm{EU}$ & $1600 \mathrm{EU}$ & $\begin{array}{l}\text { Shanghai Wilson } \\
\text { Bioengineering }\end{array}$ \\
\hline $\begin{array}{l}\text { Live attenuated, } \\
\text { freeze-dried }\end{array}$ & $\mathrm{H} 2$ & $\begin{array}{c}\text { Weisairuiji } \\
\text { Biovac-A } \\
\text { Mevac-A }\end{array}$ & None & s.c. & $6.5 \log _{10}$ & $\mathrm{CCID}_{50}$ & $\begin{array}{l}\text { Institute of Medical } \\
\text { Biology, Chinese } \\
\text { Academy of Medical } \\
\text { Sciences; Zhejiang } \\
\text { Pukang } \\
\text { Biotechnology; } \\
\text { Zhejiang Academy of } \\
\text { Medical Sciences }\end{array}$ \\
\hline $\begin{array}{l}\text { Live attenuated, } \\
\text { freeze-dried }\end{array}$ & LA-1 & HAVAC & None & s.c. & $6.5 \log _{10}$ & $\mathrm{CCID}_{50}$ & $\begin{array}{l}\text { Changchun Institute of } \\
\text { Biological Products; } \\
\text { Changchun } \\
\text { Changsheng Life } \\
\text { Sciences }\end{array}$ \\
\hline
\end{tabular}

Data modified and updated from Shouval (2010) and Cui et al. (2014).

Limited information is available for Hep-A-in-Vac: an inactivated HAV vaccine manufactured in Russia (Gorbunov et al. 1998).

i.m., intramuscular; s.c., subcutaneous.

${ }^{\text {a }}$ Some vaccine preparations are sold under multiple brand names in different countries.

${ }^{\mathrm{b}}$ EPAXAL manufacture was discontinued in 2014.

\section{ASSESSMENT OF PROTECTION AGAINST HAV FOLLOWING IMMUNIZATION}

Most HAV infections originate from ingestion of the virus in contaminated food or water, following which the virus somehow traverses the intestinal barrier and is transported to the liver via the portal circulation. Whether it undergoes replication at a primary site in the gut is unknown. Although data from humans infected with HAV are scarce, replication of the virus within liver cells generates active innate and adaptive humoral and cellular immune responses that eventually clear the virus (Walker 
et al. 2015). In contrast, viral replication does not occur after immunization with inactivated $\mathrm{HAV}$ vaccine, and protection against $\mathrm{HAV}$ is most likely primarily antibody-based. However, immunization with "killed" vaccines also leads to a measurable cellular immune response that lasts for at least 6 years and probably longer (Shouval 2010).

The minimal protective level of anti-HAV IgG is not known. By convention, humoral protection against HAV is generally assumed to have been achieved when postvaccination antiHAV IgG levels reach between 10 to $33 \mathrm{mIU} /$ $\mathrm{mL}$, depending on vaccine manufacturer and immunoassay used. In a clinical trial involving children in which both pre- and postexposure protection was shown (Werzberger et al. 1992), the geometric mean titer (GMT) of anti-HAV 4 weeks after immunization with a 25 unit dose of VAQTA was $\sim 45 \mathrm{mIU} / \mathrm{mL}$, which was indistinguishable from the anti-HAV titer in adults 7 days after administration of IG $0.06 \mathrm{~mL} / \mathrm{kg}$ (Lemon et al. 1997). Clinical evidence suggests that protection is still present for a limited period in IG recipients even in the absence of detectable anti-HAV by licensed assays. Detection of antiHAV (IgG) antibodies by qualitative assays signifies immunity to hepatitis A (Shouval 2010). Low levels of IgM anti-HAV antibodies may be detectable by conventional or experimental assays for a few weeks in $\sim 20 \%$ of recipients of inactivated HAV vaccines (Shouval et al. 1993). Therefore, screening with IgM anti-HAV assays is not a reliable means for distinguishing between acute hepatitis A and the anti-HAV antibody response to vaccination.

\section{IMMUNOGENICITY OF HAV VACCINES AND IMMUNE MEMORY}

\section{Inactivated HAV Vaccines}

Inactivated hepatitis A vaccines are highly immunogenic, irrespective of vaccine brand (Shouval 2010), and lack of a response to immunization is rare (Garner-Spitzer et al. 2009). In children and young adults, i.m. vaccination with the first of two recommended doses leads to rapid, measurable seroconversion from anti-
$\mathrm{HAV}$-negative to anti-HAV-positive in $>90 \%$ of vaccinees within 2 weeks of the priming dose (Shouval et al. 1993; Victor et al. 2007; Shouval 2010). A double-blind, randomized controlled study, comparing the Chinese inactivated TZ84 vaccine with HAVRIX in 400 healthy volunteers, showed that both vaccines provided for a $100 \%$ seroconversion rate in all 1 - to 8 -yearold children receiving two doses of vaccine during a 6-month interval (Cui et al. 2014).

Several determinants have a marginal quantitative effect on blunting of the anti-HAV response (Shouval 2010). These factors include being overweight, of advanced age, smoking, and passive transfer of anti-HAV antibodies before administration. Prior treatment with IG or passive transfer of anti-HAV antibodies from an HAV immune mother to the fetus may lead to a lower quantitative anti-HAV response to inactivated HAV vaccine. However, there is currently no evidence that such a reduced humoral immune response has a long-term impact on protection or immune memory against HAV in recipients of a full course of an inactivated vaccine. Immune suppressed individuals, such as patients with HIV infection, solid organ and stem-cell transplant recipients, and patients with chronic liver disease do respond favorably to immunization with inactivated HAV vaccine, although seroconversion rates and anti-HAV titers may be somewhat lower as compared with immune-competent vaccinees (Shouval 2010).

Concurrent administration of routine childhood or travel-related monovalent and trivalent vaccines with inactivated HAV vaccine does not interfere with immunogenicity, enhance reactogenicity, or alter the safety of the individual vaccines as long as vaccines are injected at different sites.

Long-term surveillance of immune competent vaccinees has confirmed that vaccine acquired protection following administration of two vaccine doses, injected 6-12 months apart, lasts for at least 20 years. Mathematical modeling suggests that immune memory to vaccination extends for a longer period, up to 40 years in $>90 \%$ of vaccinees (Plumb et al. 2017; Van Damme et al. 2017). Similar data have been re- 
D. Shouval

ported for a virosome-formulated HAV vaccine (Chappuis et al. 2017). Rechallenge of vaccines, 12 years after administration of a complete inactivated vaccine series, led to an anamnestic 32to 100 -fold increase in anti-HAV levels despite waning antibody titers (Van Herck et al. 2004). Thus, immune memory against HAV, established through immunization with inactivated vaccines, persists for decades in immune competent individuals. Booster doses are therefore not recommended in vaccinees who have completed a two-dose vaccination schedule (Van Damme et al. 2003). Finally, the extraordinary immunogenicity of inactivated HAV vaccines has led to the introduction of a single-dose immunization strategy in Argentina (Vizzotti et al. 2015), a pioneering step that will be discussed later in this review.

\section{Live, Attenuated Vaccines}

Two live attenuated hepatitis A vaccines, containing the $\mathrm{H} 2$ and LA-1 strains of virus, have been developed in China (Table 1) (Cui et al. 2009; Wu et al. 2012; Liu et al. 2013; Xiong et al. 2014; Zhang et al. 2016). Only limited information is available on the attenuating mutations present in the genomes of the Chinese attenuated strains of HAV (Jiang et al. 2004), but the nucleotide sequence of the $\mathrm{H} 2$ virus is remarkably similar to an attenuated HM175 strain vaccine candidate developed in Robert Purcell's laboratory at the U.S. National Institutes of Health (Karron et al. 1988; Binn and Lemon 2010). The Chinese live attenuated vaccines, administered s.c. as a single dose, have been tested in clinical trials in China (Mao et al. 1997), and have been integrated along with inactivated vaccines into the Chinese national immunization program. Immunization with a single $6.5 \log _{10}$ cell culture-infectious units dose of the live attenuated $\mathrm{H} 2$ strain led to a seroconversion rate of $94 \%$ at 2 months, remaining at $91 \%$ at month six. A recent review describes seroconversion rates of $72 \%-100 \%$ in multiple additional clinical trials performed with the $\mathrm{H} 2$ vaccine among children in China and India (Rao et al. 2016). The reported safety profile of the vaccine has generally been good. However, in one study in China,
$\mathrm{H} 2$ vaccine virus was recovered from stools of vaccine recipients as well as from 51 of 75 (71\%) contacts who were not immunized (Cui et al. 2014). In two instances, virus from contacts was subsequently passaged into marmosets. Although none of the contacts or marmosets appear to have developed frank hepatitis A, these observations raise concerns related to the ultimate stability of the attenuation phenotype of $\mathrm{H} 2$ virus during passage through humans and the possibility of reversion.

\section{VACCINE EFFICACY: PREEXPOSURE PROPHYLAXIS}

\section{Inactivated HAV Vaccines}

The efficacy of formaldehyde-inactivated HAV vaccines for preexposure prophylaxis has been established in three randomized controlled trials using HAVRIX, VAQTA, or EPAXAL. A double-blind placebo-controlled trial was conducted in the United States in 1037 children, 2-16 years old, who were at high risk for hepatitis A and who received two doses of 25 units of VAQTA or placebo at entry and 6-18 months later. A high rate of HAV infection in the study population showed $100 \%$ efficacy (95\% confidence interval [CI], 87.3\%-100\%) following the first dose of vaccine (Werzberger et al. 1992). A second study conducted in Thailand in an area with a high incidence of hepatitis $A$ compared HAVRIX and a control hepatitis B vaccine, which was administered to 40,119 children 1-16 years old. HAVRIX 360 EU/dose was administered intramuscularly at 0,1 , and 12 months. Protection against clinical hepatitis A (which was confirmed by a total anti-HAV titer $<20 \mathrm{mIU} / \mathrm{mL}$ ), was shown in $94 \%$ and $99 \%$ of seronegative vaccinees after the second and third dose, respectively (95\% CI, 79\%-99\%) (Innis et al. 1994). Inactivated HAV vaccines with different brand names and manufactured by different companies contain different viral strains, but they are interchangeable, with any substituting for a second dose in a vaccine series, as shown for HAVRIX, AVAXIM, EPAXAL, and VAQTA (Dagan et al. 2007; Soysal et al. 2007; Abarca et al. 2008). 


\section{Live Attenuated Vaccines}

Most of the clinical experience with HAV vaccines generated in China is published in the Chinese language and with the exception of a recent comprehensive review, only a limited number reports are available in English (Cui et al. 2014). Randomized controlled studies, performed between 1997 and 2003, indicated that the efficacy of the live attenuated hepatitis A vaccine (H2 strain) ranged between $94 \%$ and $100 \%$. A meta-analysis of the efficacy of live attenuated vaccines ( $\mathrm{H} 2$ and LA-1 HAV strains) included 13 randomized trials and showed that the protective efficacy was $96 \%$ (95\% CI, 93\%$98 \%$ ), which is equal to that of formaldehydeinactivated vaccines (Cui et al. 2014; Rao et al. 2016). A recent report compared anti-HAV antibody persistence following immunization with a single dose of three different vaccines in school-age children, namely, the $\mathrm{H} 2$ live attenuated Chinese vaccine, the domestic Chinese inactivated healive vaccine, and the HAVRIX inactivated vaccine (Zhang et al. 2016). Seroconversion rates were somewhat lower compared with previous reports $(64 \%, 94.4 \%$, and $73 \%$, respectively) 12 months postvaccination, compared with $1 \%$ in a control group that received one dose of an HBV vaccine. Results were similar 24 months postimmunization. It appears that seroconversion to anti-HAV positivity following a single s.c. dose of a live attenuated vaccine occurs more slowly than with inactivated vaccines, starting at 3 weeks postinoculation and reaching $74 \%-87 \%$ by week 12 and $83 \%$ at week 24 (Mao et al. 1997; Cui et al. 2014). Persistence of anti-HAV antibodies in recipients of live attenuated vaccines was documented in $72 \%-88 \%$ of recipients of the $\mathrm{H} 2$ live attenuated vaccine for a period of up to 15 years (Mao et al. 1997; Cui et al. 2009, 2014).

\section{VACCINE EFFICACY: POSTEXPOSURE PROPHYLAXIS}

Preexposure prophylaxis using inactivated or live attenuated vaccines is an effective means for prevention of a large number of infectious diseases. In contrast, the use of vaccines for post- exposure prevention is limited to a small number of vaccines with variable efficacy. The first evidence that inactivated vaccines might provide effective postexposure prophylaxis came from the pivotal efficacy trial of the inactivated HAV vaccine VAQTA, conducted in the early 1990s (Werzberger et al. 1992). The study was initiated concurrent with an outbreak of hepatitis A among children within a commune-like setting. None of the immunized children developed hepatitis more than 16 days after receiving a single 25-unit dose of VAQTA. Because the incubation period for hepatitis $A$ is on the order of 28-30 days, this suggested that the vaccine prevents hepatitis A if administered within 2 weeks of exposure (Werzberger et al. 1992). A number of clinical trials and anecdotal reports later confirmed that postexposure immunization against hepatitis A can be as effective as IG.

Effective postexposure prophylaxis with an inactivated HAV vaccine was shown in the control of an outbreak in Slovakia (Prikazsky et al. 1994), and in a controlled trial in Italy (Sagliocca et al. 1999), which revealed 79\% (95\% CI, 7\%95\%) protective efficacy in household contacts of acute hepatitis A cases. In Israel, postexposure intervention with an inactivated vaccine led to interruption of an outbreak within 2 weeks, in contrast to relatively poor performance of IG (Zamir et al. 2001). Finally, the efficacy of postexposure prophylaxis with an inactivated vaccine was established through a randomized controlled trial comparing active immunization with passive immunization with IG (Victor et al. 2007). In this trial, 1090 household and day-care contacts (2-40 years old) of index cases with acute hepatitis A were randomized to receive either inactivated hepatitis A vaccine or IG. Acute hepatitis A, confirmed by anti-HAV IgM testing, occurred in $4.4 \%$ and $3.3 \%$ of the study groups, respectively (RR 1.35 ; $95 \% \mathrm{CI}, 0.70-$ 2.67). These results led to a recommendation by the U.S. Advisory Committee on Immunization Practices (ACIP) that persons with recent ( $<2$ weeks) exposure to HAV, who have not received hepatitis A vaccine previously, should be administered either a single dose of inactivated vaccine (single antigen) or IG (Advisory Committee on Immunization Practices 2007). Al- 
D. Shouval

though not validated in controlled studies in persons older than 40 years of age, it seems likely, given the proven immunogenicity of inactivated HAV vaccines in adults, that this policy would also be appropriate for older subjects. Altogether, using inactivated hepatitis A vaccine instead of IG for postexposure prophylaxis has numerous advantages, including induction of long-term protection against hepatitis A (in contrast to IG), particularly if followed by a second dose of vaccine at 6 months, as well as ease of administration at a similar cost. At present, no data are available to support the use of live attenuated vaccines administered for postexposure prophylaxis and thus, such vaccines should only be used for prevention of HAV infection.

\section{IMMUNIZATION STRATEGIES}

Recommendations for protection against hepatitis A vary geographically and largely depend on the degree of endemicity of the disease, economic resources, and priorities of health care agencies. There are currently four strategies in use: targeted immunization of defined populations at risk, childhood vaccination in regions with increased risk of infection, universal immunization of toddlers, and single-dose immunization.

\section{Targeted Immunization of Defined Populations at Risk}

Following the licensure of the first inactivated HAV vaccines in the 1990s, initial recommendations for preexposure prophylaxis included immunization of specifically defined groups at risk for contracting hepatitis A. These groups included international travelers to areas with intermediate and high endemicity of hepatitis A, men who have sex with men (MSM), intravenous drug (i.v.) users, day-care center staff, caretakers of nonhuman primates, and patients with blood clotting disorders who receive blood-derived products. Added to this list were patients with chronic liver disease and food handlers, for whom the consequences of HAV infection can be particularly significant, either for severity of disease or transmission to others. Although this policy is still appropriate in regions of low or very high endemicity, providing individual protection to vaccinees and reducing the risk of small outbreaks, it had little impact on overall reduction of disease burden and the incidence of hepatitis A in the community.

\section{Regional Childhood Vaccination}

This strategy has been introduced in a number of countries in which the geographic distribution of HAV infection is heterogenous and where defined regions have high rates of hepatitis $A$ incidence and outbreaks compared with other neighboring areas. Three demonstration projects targeting immunization of young children, conducted in Alaskan natives, in Native Americans, and in Butte County, CA, led to 94\%-97\% reductions in the incidence of reported symptomatic acute hepatitis A within 6-10 years (Bialek et al. 2004; Wasley et al. 2005). In Alaska, the hepatitis A incidence fell to an unprecedented low of 0.1 cases $/ 100,000$ with vaccine coverage of $50 \%-80 \%$. Similar projects were introduced in Puglia, Italy in 1997 (Lopalco et al. 2000), in Catalonia, Spain in 1998 (Lopalco et al. 2000; Dominguez et al. 2003), and in North Queensland, Australia in 1999 (Hanna et al. 2004), leading to $90 \%-97 \%$ declines in the incidence of hepatitis $\mathrm{A}$ in these regions.

\section{Universal Vaccination}

The cumulative experience gained through the regional vaccination projects in pediatric populations paved the way for the introduction of a third immunization strategy, namely, universal vaccination against HAV. By 2016, 12 countries had embarked on the road toward universal HAV vaccination in young children.

In 1999, Israel became the first country worldwide to introduce universal HAV vaccination given as two doses to toddlers at 18 and 24 months of age (Dagan et al. 2005). The decision to introduce universal immunization was based on a cost-efficacy analysis as well as on the fact that the epidemiology of HAV was in transition from high-to-intermediate endemicity (Ginsberg et al. 1992). With vaccine coverage of 
$85 \%-90 \%$, the annual incidence of hepatitis A dropped by $95 \%$ within $2-3$ years of program initiation. The strategy of universal vaccination led to a marked decrease in attack rates of hepatitis A, not only in toddlers and children but in all age groups up to the age of 44 years. Consequently, universal immunization led to a shift from a state of intermediate HAV endemicity to very low endemicity with an annual incidence of 2.5 cases/100,000 (Figs. 1 and 2) (Dagan et al. 2005; Chodick et al. 2008; Barkai et al. 2009).

It should be noted that despite the remarkable impact of universal immunization on the incidence of hepatitis A in Israel, HAV still circulates in the sewage system in the major cities, suggesting continuous import of virus from nearby geographic regions that have not yet introduced universal immunization (Manor et al. 2016). The presence of virus in sewage system demands continuous surveillance, as the declining incidence of HAV infection has led to increased susceptibility in older, nonimmunized populations.

In 1999, the ACIP released a recommendation to immunize all children in 11 southwestern U.S. states with the highest reported incidence of hepatitis A nationally ( $>20$ cases/ 100,000) (Advisory Committee on Immunization Practices 1999). Despite a relatively low vaccine coverage, this action led to a decline of acute hepatitis A cases $<5 / 100,000$ cases within a short period of time (Fig. 3). As in Israel, the incidence of hepatitis A was reduced, not only in children, but also in adults, reflecting the important role of diapered infants and young children in transmission of the infection. In 2006, the recommendation to immunize children over the age of 1 year was extended to the entire United States (Advisory Committee on Immunization Practices 2006).

A summary of the cost effectiveness of various immunization strategies described in 31 studies was published by the World Health Organization (WHO) in 2012 (WHO 2012). Universal immunization was particularly cost-effective in children, especially in high incidence regions with all reported cost-effectiveness ratios decreasing below approximately U.S. $\$ 35,000$ per quality-adjusted life year (QALY).
A recent review of 27 studies conducted in countries that introduced universal immunization confirmed the impressive impact of introduction of universal immunization on the incidence of HAV infection. All studies, except one, showed a marked reduction in the incidence of hepatitis A with a decline of infection also in nonvaccinated populations (Stuurman et al. 2017). In summary, although complete eradication of HAV worldwide remains an elusive goal, available data suggest that universal childhood immunization is the most efficient and appropriate public health measure for prevention of hepatitis A in many regions of the world. This approach is of particular benefit for countries with intermediate HAV endemicity or countries in transition from high to intermediate endemicity of infection.

\section{Single-Dose Immunization}

Despite favorable cost/benefit analyses that justify introduction of universal immunization in regions at risk, the cost of universal immunization using two doses of an inactivated HAV vaccine is still prohibitive for many countries. In 2005, Argentina became the first country to introduce universal immunization of children at 12 months of age using a single dose of inactivated vaccine (Vizzotti et al. 2015). This decision was supported by several reports suggesting that anti-HAV seroprotection rates following the priming dose of inactivated HAV vaccines may reach $88 \%$ within 2 weeks, rising to $97 \%$ $100 \%$ within several months before administration of the booster dose (Van Damme et al. 1994; Ashur et al. 1999; Vacchino 2008; Shouval 2010). The impact of this single-dose immunization strategy was similar to the one observed in Israel following the introduction of a twodose universal immunization strategy. The original baseline incidence of hepatitis A in Argentina dropped from 70.5 to 173.8 cases/100,000 between 1995 and 2004 to 10 cases/100,000 in all age groups within a few years, representing a $>80 \%$ decrease in incidence (Fig. 4) (Vizzotti et al. 2014, 2015; Uruena et al. 2016). In addition, the rate of liver transplantation for fulminant hepatitis A has dropped in Argentina. 


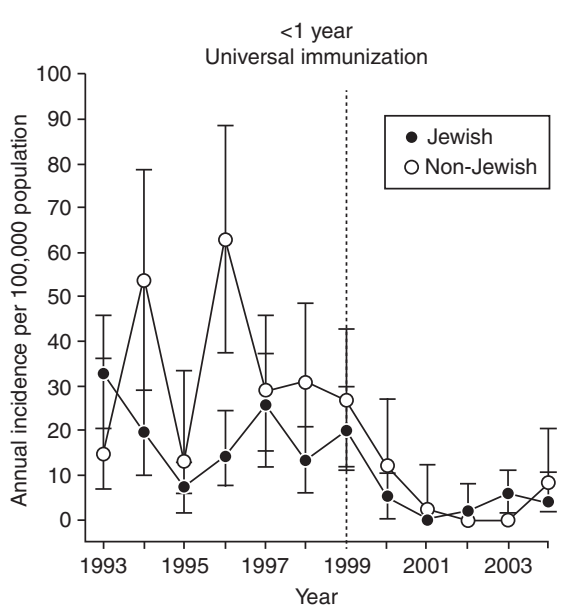

10-14 years

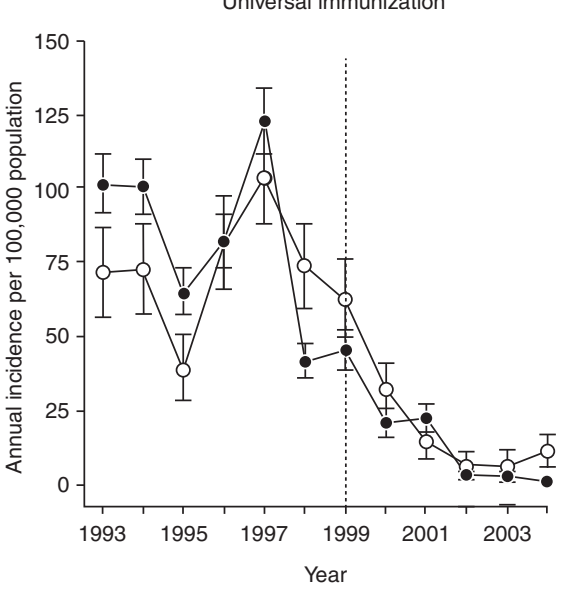

Figure 1. Impact of universal immunization on the annual age-specific incidences (ages $<1-64$ years) of reported hepatitis A disease among Jewish and non-Jewish populations in Israel, 1993-2004. Error bars indicate 95\% confidence intervals. (From Dagan et al. 2005; reproduced, with permission, from JAMA ๔ 2005.) 


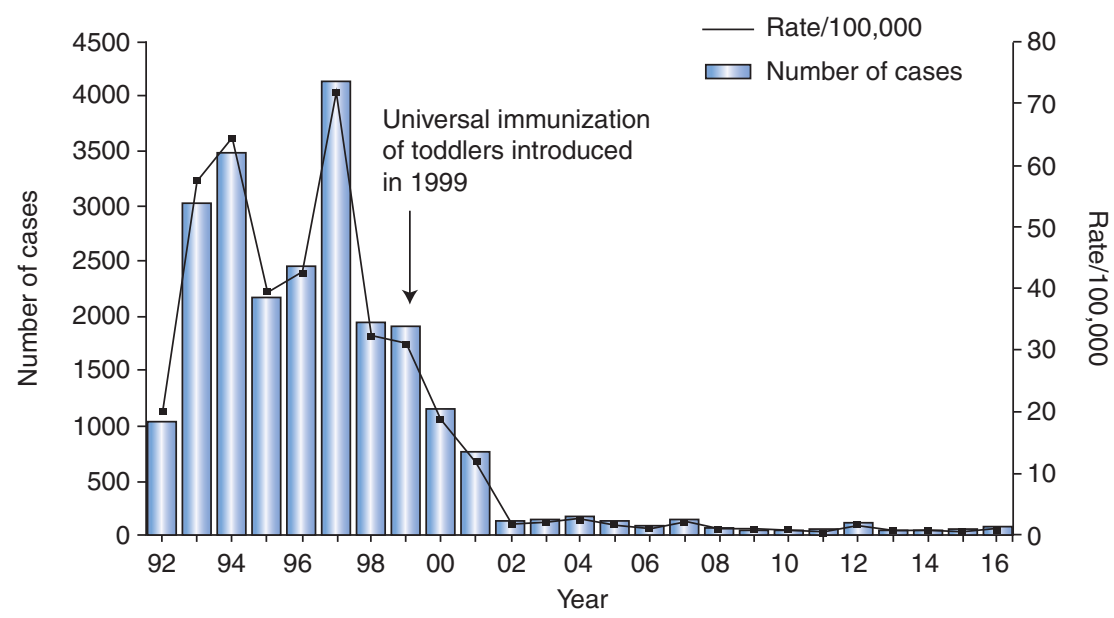

Figure 2. Impact of universal immunization on incidence of acute hepatitis A in Israel between January 1992 and December 2016. Universal immunization was started in 1999 with administration of an inactivated hepatitis A virus (HAV) vaccine at 18 and 24 months of age. Data collected through passive surveillance by the Israeli Ministry of Health (MOH). (Received courtesy of Dr. E. Anis, MOH, Israel.) (From Lemon et al. 2017; reproduced, with permission, from Elsevier (c) 2017.)

This single-dose immunization strategy is now being adopted by several countries in Latin America. In Nicaragua, a randomized, placebocontrolled, double-blind trial of a single dose of EPAXAL, a virosome-formulated, alum-free, inactivated HAV vaccine, was conducted in 274 children (Mayorga Perez et al. 2003). Children (age range 1.5-6 years) received vaccine or placebo injections. HAV infection was diagnosed by the presence of IgM anti-HAV in four children in the vaccine group, and 22 children in the placebo group, revealing a protective efficacy of 84.6\% (95\% CI, 54.7\%-96.1\%); protection was $100 \%$ by week 6 after immunization.

In contrast to the two-dose schedule usually used for inactivated HAV vaccines, the standard schedule for live attenuated HAV vaccine is a single dose, as used in China, India, and some

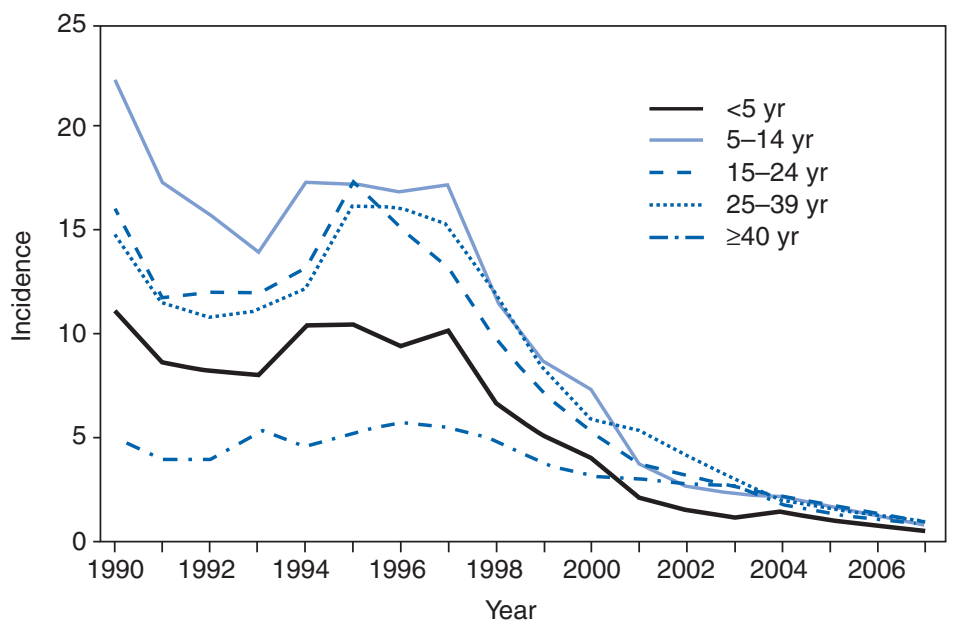

Figure 3. Hepatitis A incidence in the United States by year, 1990-2007. (From Daniels et al. 2009; reproduced courtesy of the Centers for Disease Control and Prevention.) 
D. Shouval

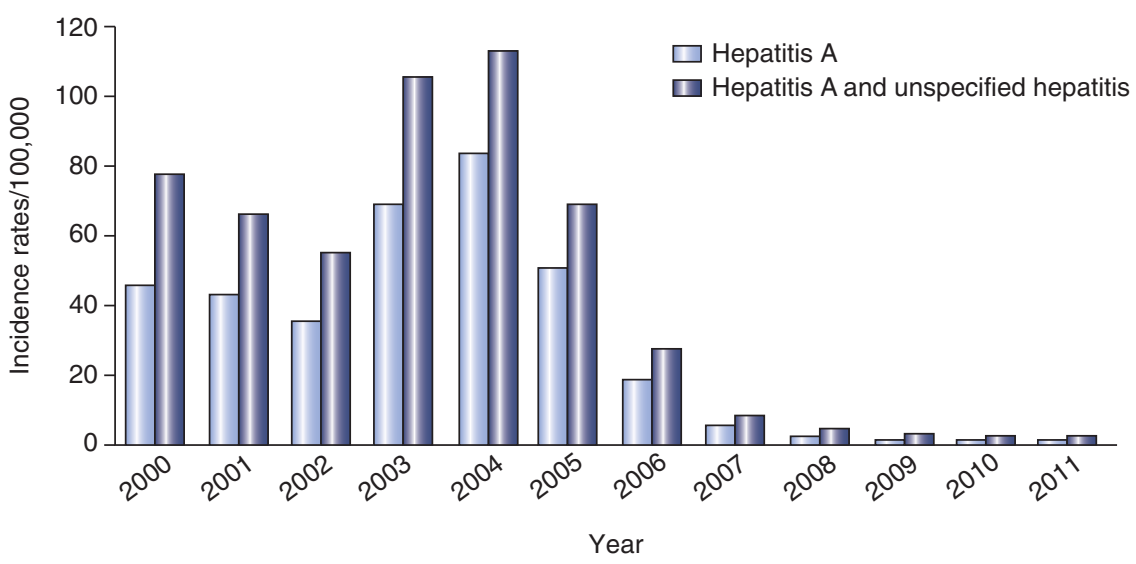

Figure 4. Impact of the single-dose immunization strategy against hepatitis A in Argentina. (From Lemon et al. 2017; reproduced, with permission, from Elsevier (c) 2017.)

other countries as described above (Cui et al. 2014).

\section{SAFETY OF HEPATITIS A VACCINES}

\section{Inactivated HAV Vaccines}

Inactivated $\mathrm{HAV}$ vaccines have had an excellent record of safety and tolerability in children and adults alike and are interchangeable for use in booster doses (Shouval 2010). Almost 200 million doses of inactivated hepatitis A vaccine were sold worldwide between 1995 and early 2006 . Adverse reactions are generally mild, and most often confined to local irritation at the site of injection; headache has also been reported as well as irritability in young children. Based on the cumulative experience gained until 2006, the overall safety profile of all formaldehyde-inactivated hepatitis A vaccines reported in the present review, irrespective of manufacturers, is excellent. Comprehensive safety data can be found in recommendations from the ACIP (Advisory Committee on Immunization Practices 2006), a WHO report on the immunologic basis of immunization (Shouval 2010), and the review from Cui et al. (2014).

\section{Live Attenuated HAV Vaccines}

As of 2010, freeze-dried live-attenuated hepatitis $\mathrm{A}$ vaccines had been given to $>80$ million people, mainly children, in China. Only 12 cases of mild adverse reactions were reported directly to the manufacturers from 2007 through 2009, and no fatalities or serious reactions were reported to the Chinese Center for Disease Control and Prevention (CDC) (Cui et al. 2014). Postmarketing surveillance revealed that local and systemic adverse events in recipients of live attenuated HAV vaccines in China were similar to those reported for the recipients of Chinese inactivated HAV vaccines. However, the well-documented transmission of vaccine virus to close contacts of recipients of live attenuated vaccines remains a concern. Although reversion to virulence has not been reported, this requires further study, as does the degree of secondary spread of virus to nonimmune persons.

\section{CONCLUDING REMARKS}

In can be stated without reservation that hepatitis A vaccines are among the most immunogenic, safest, and well-tolerated vaccines ever produced. Immunization leads to long-lasting protection against acute hepatitis A. Strategies for immunization should be tailored to individual countries, based on endemicity of HAV infection, available resources, and public health priorities. Cumulative experience suggests that universal immunization of toddlers is the most efficient mean for prevention of hepatitis $\mathrm{A}$ in 
countries in transition from high to intermediate endemicity of HAV infection.

\section{REFERENCES}

Abarca K, Ibanez I, Perret C, Vial P, Zinsou JA. 2008. Immunogenicity, safety, and interchangeability of two inactivated hepatitis A vaccines in Chilean children. Int J Infect Dis 12: 270-277.

Advisory Committee on Immunization Practices. 1999. Prevention of hepatitis A through active or passive immunization: Recommendations of the Advisory Committee on Immunization Practices (ACIP). MMWR Recomm Rep 48: $1-37$.

Advisory Committee on Immunization Practices. 2006. Prevention of hepatitis A through active or passive immunization: Recommendations of the Advisory Committee on Immunization Practices (ACIP). MMWR Recomm Rep 55: $1-23$.

Advisory Committee on Immunization Practices. 2007. Update: Prevention of hepatitis A after exposure to hepatitis $A$ virus and in international travelers. Updated recom mendations of the Advisory Committee on Immunization Practices (ACIP). MMWR Morb Mortal Wkly Rep 19: 1080-1084.

Ashur Y, Adler R, Rowe M, Shouval D. 1999. Comparison of immunogenicity of two hepatitis A vaccines-VAQTA and HAVRIX - in young adults. Vaccine 17: 2290-2296.

Barkai G, Belmaker I, Givon-Lavi N, Dagan R. 2009. The effect of universal toddlers-only hepatitis A virus vaccination program on seropositivity rate in unvaccinated toddlers: Evidence for reduced virus circulation in the community. Pediatr Infect Dis J 28: 391-393.

Bialek SR, Thoroughman DA, Hu D, Simard EP, Chattin J, Cheek J, Bell BP. 2004. Hepatitis A incidence and hepatitis a vaccination among American Indians and Alaska Natives, 1990-2001. Am J Public Health 94: 996-1001.

Binn LN, Lemon SM. 2010. Hepatitis A. In Vaccines, a biography (ed. Artenstein AW), pp. 335-346. Springer, New York.

Chappuis F, Farinelli T, Deckx H, Sarnecki M, Go O, Salzgeber Y, Stals C. 2017. Immunogenicity and estimation of antibody persistence following vaccination with an inactivated virosomal hepatitis A vaccine in adults: A 20-year follow-up study. Vaccine 35: 1448-1454.

Chodick G, Heymann AD, Ashkenazi S, Kokia E, Shalev V. 2008. Long-term trends in hepatitis A incidence following the inclusion of hepatitis A vaccine in the routine nationwide immunization program. J Viral Hepat 15: 62-65.

Cui F, Hadler SC, Zheng H, Wang F, Zhenhua W, Yuansheng H, Gong X, Chen Y, Liang X. 2009. Hepatitis A surveillance and vaccine use in China from 1990 through 2007. J Epidemiol 19: 189-195.

Cui F, Liang X, Wang F, Zheng H, Hutin YJ, Yang W. 2014. Development, production, and postmarketing surveillance of hepatitis A vaccines in China. J Epidemiol 24: 169-177.

Dagan R, Leventhal A, Anis E, Slater P, Ashur Y, Shouval D. 2005. Incidence of hepatitis A in Israel following universal immunization of toddlers. JAMA 294: 202-210.
Dagan R, Amir J, Livni G, Greenberg D, Abu-Abed J, Guy L, Ashkenazi S, Foresner G, Tewald F, Schatzl HM, et al. 2007. Concomitant administration of a virosome-adjuvanted hepatitis a vaccine with routine childhood vaccines at age twelve to fifteen months: A randomized controlled trial. Pediatr Infect Dis J 26: 787-793.

Daniels D, Grytdal S, Wasley A; Centers for Disease Control and Prevention (CDC). 2009. Surveillance for acute viral hepatitis-United States, 2007. MMWR Surveill Summ 58: $1-27$.

Dominguez A, Salleras L, Carmona G, Batalla J. 2003. Effectiveness of a mass hepatitis A vaccination program in preadolescents. Vaccine 21: 698-701.

Ellis EF, Henney CS. 1969. Adverse reactions following administration of human $\gamma$ globulin. J Allergy 43: 45-54.

Emerson SU, Huang YK, Nguyen H, Brockington A, Govindarajan S, St Claire M, Shapiro M, Purcell RH. 2002. Identification of $\mathrm{VP} 1 / 2 \mathrm{~A}$ and $2 \mathrm{C}$ as virulence genes of hepatitis A virus and demonstration of genetic instability of 2C. J Virol 76: 8551-8559.

Feinstone S, Kapikian AZ, Purcell RH. 1973. Hepatitis A: Detection by immune electron microscopy of a viruslike antigen associated with acute illness. Science 182: 1026.

Feng Z, Hensley L, McKnight KL, Hu F, Madden V, Ping L, Jeong SH, Walker C, Lanford RE, Lemon SM. 2013. A pathogenic picornavirus acquires an envelope by hijacking cellular membranes. Nature 496: 367-371.

Ferguson M, Sands D, Lelie N. 2000. Hepatitis A immunoglobulin: An international collaborative study to establish the second international standard. Biologicals 28: 233240 .

Funkhouser AW, Purcell RH, D'Hondt E, Emerson SU. 1994. Attenuated hepatitis A virus: Genetic determinants of adaptation to growth in MRC-5 cells. J Virol 68: 148157.

Garner-Spitzer E, Kundi M, Rendi-Wagner P, Winkler B, Wiedermann G, Holzmann H, Herzog C, Kollaritsch H, Wiedermann U. 2009. Correlation between humoral and cellular immune responses and the expression of the hepatitis A receptor HAVcr-1 on T cells after hepatitis A revaccination in high and low-responder vaccinees. Vaccine 27: 197-204.

Ginsberg GM, Berger S, Shouval D. 1992. Cost-benefit analysis of a nationwide inoculation programme against viral hepatitis B in an area of intermediate endemicity. Bull World Health Organ 70: 757-767.

Gorbunov MA, Pavlova LI, Rozhkov SD, Kukharev AI, Novikov V, Karpovich LG, Kalashnikova TV, Bektimirov TA Zelenov IA, Levina VD, et al. 1998. Hep-A-in-Vac, a Russian cultured concentrated inactivated vaccine against hepatitis A. Zh Mikrobiol Epidemiol Immunobiol 1: 5054.

Green MS, Cohen D, Lerman Y, Sjogren M, Binn LN, Zur S, Slepon R, Robin G, Hoke C, Bancroft W, et al. 1993 Depression of the immune response to an inactivated hepatitis A vaccine administered concomitantly with immune globulin. J Infect Dis 168: 740-743.

Hanna JN, Hills SL, Humphreys JL. 2004. Impact of hepatitis A vaccination of Indigenous children on notifications of hepatitis A in North Queensland. Med J Aust 181: 482 485. 
D. Shouval

Hilleman MR. 1993. Hepatitis and hepatitis A vaccine: A glimpse of history. J Hepatol 18: S5-S10.

Innis BL, Snitbhan R, Kunasol P, Laorakpongse T, Poopatanakool W, Kozik CA, Suntayakorn S, Suknuntapong T, Safary A, Tang DB, et al. 1994. Protection against hepatitis A by an inactivated vaccine. JAMA 271: 1328-1334.

Jiang CL, Wang PF, Liu JY, Zhang HY, Wan ZJ. 2004. Genomic sequence of hepatitis A virus L-A-1 vaccine strain Zhonghua Shi Yan He Lin Chuang Bing Du Xue Za Zhi 18: $360-362$.

Karron RA, Daemer R, Ticehurst J, D’Hondt E, Popper H, Mihalik K, Phillips J, Feinstone S, Purcell RH. 1988. Studies of prototype live hepatitis A virus vaccines in primate models. J Infect Dis 157: 338-345.

Krugman S. 1976. Effect of human immune serum globulin on infectivity of hepatitis A virus. J Infect Dis 134: 70-74.

Kumru OS, Joshi SB, Smith DE, Middaugh CR, Prusik T, Volkin DB. 2014. Vaccine instability in the cold chain Mechanisms, analysis and formulation strategies. Biologicals 42: 237-259.

Lemon SM, Murphy PC, Provost PJ, Chalikonda I, Davide JP, Schofield TL, Nalin DR, Lewis JA. 1997. Immunoprecipitation and virus neutralization assays demonstrate qualitative differences between protective antibody responses to inactivated hepatitis $\mathrm{A}$ vaccine and passive immunization with immune globulin. J Infect Dis 176: 9-19.

Lemon SM, Ott J, Van Damme P, Shouval D. 2017. Hepatitis A. J Hepatol doi: 10.1016/j.jhep.2017.08.034.

Liu JP, Nikolova D, Fei Y. 2009. Immunoglobulins for preventing hepatitis A. Cochrane Database Syst Rev 15: CD004181.

Liu XE, Wushouer F, Gou A, Kuerban M, Li X, Sun Y, Zhang J, Liu Y, Li J, Zhuang H. 2013. Comparison of immunogenicity between inactivated and live attenuated hepatitis A vaccines: A single-blind, randomized, parallel-group clinical trial among children in Xinjiang Uighur Autonomous Region, China. Hum Vaccin Immunother 9: 14601465.

Lopalco PL, Salleras L, Barbuti S, Germinario C, Bruguera M, Buti M, Dominguez A. 2000. Hepatitis A and B in children and adolescents-What can we learn from $\mathrm{Pu}$ glia (Italy) and Catalonia (Spain)? Vaccine 19: 470-474.

Manor Y, Lewis M, Ram D, Daudi N, Mor O, Savion M, KraOz Z, Avni YS, Sheffer R, Shouval D, et al. 2016. Evidence for hepatitis A virus endemic circulation in Israel despite universal toddler vaccination since 1999 and low clinical incidence in all age groups. J Infect Dis 215: 574-580.

Mao JS, Chai SA, Xie RY, Chen NL, Jiang Q, Zhu XZ, Zhang SY, Huang HY, Mao HW, Bao XN, et al. 1997. Further evaluation of the safety and protective efficacy of live attenuated hepatitis A vaccine (H2-strain) in humans. Vaccine 15: 944-947.

Martin A, Lemon SM. 2006. Hepatitis A virus: From discovery to vaccines. Hepatology 43: S164-S172.

Mayorga Perez O, Herzog C, Zellmeyer M, Loaisiga A, Frosner G, Egger M. 2003. Efficacy of virosome hepatitis A vaccine in young children in Nicaragua: Randomized placebo-controlled trial. J Infect Dis 188: 671-677.

Morgeaux S, Manniam I, Variot P, Buchheit KH, Daas A, Wierer M, Costanzo A. 2015. Establishment of hepatitis A vaccine (inactivated, non-adsorbed) BRP batches 2 and 3 . Pharmeur Bio Sci Notes 2015: 118-130.

Nainan OV, Xia G, Vaughan G, Margolis HS. 2006. Diagnosis of hepatitis a virus infection: A molecular approach. Clin Microbiol Rev 19: 63-79.

Plumb ID, Bulkow LR, Bruce MG, Hennessy TW, Morris J, Rudolph K, Spradling P, Snowball M, McMahon BJ. 2017. Persistence of antibody to hepatitis A virus 20 years after receipt of hepatitis A vaccine in Alaska. J Viral Hepat 24: 608-612.

Prikazsky V, Olear V, Cernoch A, Safary A, Andre FE. 1994. Interruption of an outbreak of hepatitis $\mathrm{A}$ in two villages by vaccination. J Med Virol 44: 457-459.

Provost PJ, Hilleman MR. 1979. Propagation of human hepatitis A virus in cell culture in vitro. Proc Soc Exp Biol Med 160: 213-221.

Purcell RH, D’Hondt E, Bradbury R, Emerson SU, Govindarajan S, Binn L. 1992. Inactivated hepatitis A vaccine: Active and passive immunoprophylaxis in chimpanzees. Vaccine 10: S148-S151.

Rao S, Mao JS, Motlekar S, Fangcheng Z, Kadhe G. 2016. A review of immunogenicity and tolerability of live attenuated Hepatitis A vaccine in children. Hum Vaccin Immunother 12: 3160-3165.

Sagliocca L, Amoroso P, Stroffolini T, Adamo B, Tosti ME, Lettieri G, Esposito C, Buonocore S, Pierri P, Mele A. 1999. Efficacy of hepatitis A vaccine in prevention of secondary hepatitis A infection: A randomised trial. Lancet 353: 1136-1139.

Shouval D. 2010. The immunological basis for immunization series. In Immunization vaccines and biologicals, pp. 1-39. World Health Organization, Geneva.

Shouval D, Ashur Y, Adler R, Lewis JA, Armstrong ME, Davide JP, McGuire B, Kuter B, Brown L, Miller W, et al. 1993. Single and booster dose responses to an inactivated hepatitis A virus vaccine: Comparison with immune serum globulin prophylaxis. Vaccine 11: S9-S14.

Soysal A, Gokce I, Pehlivan T, Bakir M. 2007. Interchangeability of a hepatitis A vaccine second dose: Avaxim 80 following a first dose of Vaqta 25 or Havrix 720 in children in Turkey. Eur J Pediatr 166: 533-539.

Stalder J, Costanzo A, Daas A, Rautmann G, Buchheit KH. 2010. Establishment of a biological reference preparation for hepatitis A vaccine (inactivated, non-adsorbed). Pharmeur Bio Sci Notes 2010: 15-29.

Stokes J, Blanchard M, et al.Neefe JR, Gellis SS, Wade GR. 1948. Methods of protection against homologous serum hepatitis; studies on the protective value of gamma globulin in homologous serum hepatitis Sh virus. JAMA 138: 336-341.

Stuurman AL, Marano C, Bunge EM, De Moerlooze L, Shouval D. 2017. Impact of universal mass vaccination with monovalent inactivated hepatitis A vaccines-A systematic review. Hum Vaccin Immunother 13: 724-736.

Tejada-Strop A, Costafreda MI, Dimitrova Z, Kaplan GG, Teo CG. 2017. Evaluation of potencies of immune globulin products against hepatitis A. JAMA Intern Med 177: 430-432.

Uruena A, Gonzalez JE, Rearte A, Perez Carrega ME, Calli R, Pagani MF, Uboldi A, Vicentin R, Caglio P, Canero-Velasco MC, et al. 2016. Single-dose universal hepatitis A 
immunization in one-year-old children in Argentina High prevalence of protective antibodies up to 9 years after vaccination. Pediatr Infect Dis J 35: 1339-1342.

Vacchino MN. 2008. Incidence of Hepatitis A in Argentina after vaccination. J Viral Hepat 15: 47-50.

Van Damme P, Van Herck K. 2004. A review of the efficacy, immunogenicity and tolerability of a combined hepatitis A and B vaccine. Expert Rev Vaccines 3: 249-267.

Van Damme P, Mathei C, Thoelen S, Meheus A, Safary A, Andre FE. 1994. Single dose inactivated hepatitis A vaccine: Rationale and clinical assessment of the safety and immunogenicity. J Med Virol 44: 435-441.

Van Damme P, Banatvala J, Fay O, Iwarson S, McMahon B, Van Herck K, Shouval D, Bonanni P, Connor B, Cooksley G, et al. 2003. Hepatitis A booster vaccination: Is there a need? Lancet 362: 1065-1071.

Van Damme P, Leroux-Roels G, Suryakiran P, Folschweiller N, Van Der Meeren O. 2017. Persistence of antibodies 20 $\mathrm{y}$ after vaccination with a combined hepatitis $\mathrm{A}$ and $\mathrm{B}$ vaccine. Hum Vaccin Immunother 13: 972-980.

Van Herck K, Van Damme P, Lievens M, Stoffel M. 2004. Hepatitis A vaccine: Indirect evidence of immune memory 12 years after the primary course. J Med Virol 72: 194196.

Victor JC, Monto AS, Surdina TY, Suleimenova SZ, Vaughan G, Nainan OV, Favorov MO, Margolis HS, Bell BP. 2007. Hepatitis A vaccine versus immune globulin for postexposure prophylaxis. N Engl J Med 357: 1685 1694.

Vizzotti C, Gonzalez J, Gentile A, Rearte A, Ramonet M, Canero-Velasco MC, Perez Carrega ME, Uruena A, Diosque M. 2014. Impact of the single-dose immunization strategy against hepatitis A in Argentina. Pediatr Infect Dis J 33: 84-88.

Vizzotti C, Gonzalez J, Rearte A, Uruena A, Perez Carrega M, Calli R, Gentile A, Uboldi A, Ramonet M, Canero-Velasco M, et al. 2015. Single-dose universal hepatitis A immunization in Argentina: Low viral circulation and high persistence of protective antibodies up to 4 years. $J$ Pediatric Infect Dis Soc 4: e62-e67.

Walker CM, Feng Z, Lemon SM. 2015. Reassessing immune control of hepatitis A virus. Curr Opin Virol 11: 7-13.

Wasley A, Samandari T, Bell BP. 2005. Incidence of hepatitis $\mathrm{A}$ in the United States in the era of vaccination. JAMA 294: 194-201.

Werzberger A, Mensch B, Kuter B, Brown L, Lewis J, Sitrin R, Miller W, Shouval D, Wiens B, Calandra G, et al. 1992. A controlled trial of a formalin-inactivated hepatitis A vaccine in healthy children. $N$ Engl J Med 327: 453-457.

WHO. 2012. WHO position paper on hepatitis A vaccines. Wkly Epidemiol Rec 87: 261-276.

Wu JY, Liu Y, Chen JT, Xia M, Zhang XM. 2012. Review of 10 years of marketing experience with Chinese domestic inactivated hepatitis A vaccine healive. Hum Vaccin Immunother 8: 1836-1844.

Xiong LS, Shi Q, Gong XR, Cui Y, Chen MH. 2014. The spectra, symptom profiles and overlap of Rome III functional gastrointestinal disorders in a tertiary center in South China. J Dig Dis 15: 538-544.

Xu ZY, Wang XY. 2014. Live attenuated hepatitis A vaccines developed in China. Hum Vaccin Immunother 10: 659666.

Zaaijer HL, Leentvaar-Kuijpers A, Rotman H, Lelie PN. 1993. Hepatitis A antibody titres after infection and immunization: Implications for passive and active immunization. J Med Virol 40: 22-27.

Zamir C, Rishpon S, Zamir D, Leventhal A, Rimon N, BenPorath E. 2001. Control of a community-wide outbreak of hepatitis A by mass vaccination with inactivated hepatitis A vaccine. Eur J Clin Microbiol Infect Dis 20: 185-187.

Zhang X, An J, Tu A, Liang X, Cui F, Zheng H, Tang Y, Liu J, Wang X, Zhang N, et al. 2016. Comparison of immune persistence among inactivated and live attenuated hepatitis a vaccines 2 years after a single dose. Hum Vaccin Immunother 12: 2322-2326. 


\section{$\&_{\mathrm{CSH}}^{\infty} \&$ Cold Spring Harbor

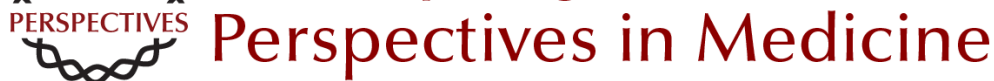

\section{Immunization against Hepatitis A}

Daniel Shouval

Cold Spring Harb Perspect Med 2019; doi: 10.1101/cshperspect.a031682 originally published online April 16, 2018

\section{Subject Collection Enteric Hepatitis Viruses}

Hepatitis A Virus Genome Organization and Replication Strategy

Kevin L. McKnight and Stanley M. Lemon

Adaptive Immune Responses in Hepatitis A Virus and Hepatitis E Virus Infections

Christopher M. Walker

Small Animal Models of Hepatitis E Virus Infection Tian-Cheng Li and Takaji Wakita

Acute and Persistent Hepatitis E Virus Genotype 3 and 4 Infection: Clinical Features, Pathogenesis, and Treatment Nassim Kamar and Sven Pischke

Epidemiology of Genotype 1 and 2 Hepatitis E Virus Infections

Kenrad E. Nelson, Alain B. Labrique and Brittany L. Kmush

History of the Discovery of Hepatitis A Virus Stephen M. Feinstone

Epidemiology and Transmission of Hepatitis A Virus and Hepatitis E Virus Infections in the United States

Megan G. Hofmeister, Monique A. Foster and Eyasu H. Teshale

Stem Cell-Derived Culture Models of Hepatitis E Virus Infection

Viet Loan Dao Thi, Xianfang Wu and Charles M. Rice
Evolutionary Origins of Enteric Hepatitis Viruses Anna-Lena Sander, Victor Max Corman, Alexander N. Lukashev, et al.

Enterically Transmitted Non-A, Non-B Hepatitis and the Discovery of Hepatitis E Virus

Stanley M. Lemon and Christopher M. Walker

Natural History, Clinical Manifestations, and

Pathogenesis of Hepatitis E Virus Genotype 1 and

2 Infections

Rakesh Aggarwal and Amit Goel

Hepatitis A Virus and Hepatitis E Virus: Emerging and Re-Emerging Enterically Transmitted

Hepatitis Viruses Stanley M. Lemon and Christopher M. Walker

Hepatitis A Virus Capsid Structure David I. Stuart, Jingshan Ren, Xiangxi Wang, et al.

Comparative Pathology of Hepatitis A Virus and Hepatitis E Virus Infection John M. Cullen and Stanley M. Lemon

Innate Immunity to Enteric Hepatitis Viruses Zongdi Feng and Stanley M. Lemon

Nonhuman Primate Models of Hepatitis A Virus and Hepatitis E Virus Infections

Robert E. Lanford, Christopher M. Walker and Stanley M. Lemon

For additional articles in this collection, see http://perspectivesinmedicine.cshlp.org/cgi/collection/ 